\title{
Non-invasive Imaging of Human Embryonic Stem Cells
}

\author{
Hao Hong ${ }^{\mathrm{a}}$, Yunan Yang ${ }^{\mathrm{a}}$, Yin Zhang ${ }^{\mathrm{b}}$, and Weibo Cai ${ }^{\mathrm{a}, \mathrm{b}, \mathrm{c},{ }^{*}}$ \\ aDepartment of Radiology, School of Medicine and Public Health, University of Wisconsin - \\ Madison, Madison, Wisconsin, USA \\ bDepartment of Medical Physics, School of Medicine and Public Health, University of Wisconsin - \\ Madison, Madison, Wisconsin, USA \\ 'University of Wisconsin Carbone Cancer Center, Madison, Wisconsin, USA
}

\begin{abstract}
Human embryonic stem cells (hESCs) hold tremendous therapeutic potential in a variety of diseases. Over the last decade, non-invasive imaging techniques have proven to be of great value in tracking transplanted hESCs. This review article will briefly summarize the various techniques used for non-invasive imaging of hESCs, which include magnetic resonance imaging (MRI), bioluminescence imaging (BLI), fluorescence, single-photon emission computed tomography (SPECT), positron emission tomography (PET), and multimodality approaches. Although the focus of this review article is primarily on hESCs, the labeling/tracking strategies described here can be readily applied to other (stem) cell types as well. Non-invasive imaging can provide convenient means to monitor hESC survival, proliferation, function, as well as overgrowth (such as teratoma formation), which could not be readily investigated previously. The requirement for hESC tracking techniques depends on the clinical scenario and each imaging technique will have its own niche in preclinical/clinical research. Continued evolvement of non-invasive imaging techniques will undoubtedly contribute to significant advances in understanding stem cell biology and mechanisms of action.
\end{abstract}

\section{Keywords}

Human embryonic stem cells (hESCs); molecular imaging; regenerative medicine; cell tracking; bioluminescence imaging (BLI); positron emission tomography (PET); single-photon emission computed tomography (SPECT); magnetic resonance imaging (MRI)

\section{INTRODUCTION}

Human embryonic stem cells (hESCs), capable of self-renewal and differentiation into virtually all cell types with proper conditioning [1], are extremely valuable sources for regenerative therapies in the clinic [2-4]. HESCs can be used in a variety of scenarios such as cardiovascular diseases [5], neural disorders [6,7], bone/cartilage diseases [8], among others. One of the most common applications for hESCs is hESC-derived myocardium cells which can be used for myocardium transplantation $[9,10]$. However, the low efficiency of cardiomyocyte formation from hESCs significantly hampers the potential clinical use. Over the last decade, many strategies have been developed and optimized for hESC derivation [7, 8].

\footnotetext{
${ }^{*}$ Requests for reprints: Departments of Radiology and Medical Physics, School of Medicine and Public Health, University of Wisconsin - Madison, 1111 Highland Ave, Room 7137, Madison, WI 53705-2275, USA. wcai@uwhealth.org; Fax: 1-608-265-0614; Tel: 1-608-262-1749. .
} 
Despite all the achievements that have been made over the last decade, stem cell biology is still not completely understood and the mechanisms of cell differentiation and self-renewal have not been fully characterized. There are many inconsistent, sometimes contradictory results observed in hESC-based research such as those focused on myocardium transplantation $[11,12]$. Two major concerns in the clinical implementation of $\mathrm{hESC}$ transplantation therapy are the possibility of teratoma formation from undifferentiated hESCs and the host immune responses to allogenic cells [13]. To better understand the in vivo behavior and true therapeutic power of hESC or hESC-derived cells, an accurate and sensitive tool for monitoring these cells is needed. Investigating in vivo hESC behavior and the ultimate feasibility of cell transplantation therapy necessitates the development of novel imaging techniques to longitudinally monitor hESC localization, proliferation, and viability in living subjects.

Molecular imaging, "the visualization, characterization and measurement of biological processes at the molecular and cellular levels in humans and other living systems" [14], is an extremely powerful tool in hESC-based research. Molecular imaging typically includes molecular magnetic resonance imaging (MRI), magnetic resonance spectroscopy (MRS), optical bioluminescence, optical fluorescence, targeted ultrasound, single-photon emission computed tomography (SPECT), and positron emission tomography (PET) $[15,16]$. Continued development and wider availability of scanners dedicated to small animal imaging studies, which can provide a similar in vivo imaging capability in mice, primates, and human, can enable smooth transfer of knowledge and molecular measurements between species thereby facilitating clinical translation. This review article will briefly summarize the current status of non-invasive imaging of hESCs, most of which is based on MRI and bioluminescence imaging (BLI). The majority of the imaging techniques discussed in this review can also be applicable to the tracking/imaging of other (stem) cells. Here we will only focus on hESC and its derivatives which can serve as an example for non-invasive cell imaging/tracking in general.

\section{IMAGING hESCS WITH MRI}

MRI, a frequently used tool for in vivo imaging of transplanted cells, was among the first imaging modalities applied for monitoring the cellular actions of hESCs in vitro and in vivo. The most widely-used labels for MRI of stem cells are superparamagnetic iron oxide (SPIO) nanoparticles and many different labeling strategies have been developed over the last decade $[17,18]$. SPIO can be detected at a comparatively low concentration $(5-10 \mu \mathrm{M}$ of $\mathrm{Fe})$ [19]. More importantly, certain SPIO formulations have been approved by the Food and Drug Administration (FDA) for clinical use which makes it much easier to image hESCs in patients using SPIO as a label, as compared with the other techniques for cell tracking.

MRI has been reported for long-term tracking of hESCs [20]. HESCs magnetically labeled by dextran-coated ferrum-oxide particles were investigated both ex vivo (after transplantation of $\sim 100,000$ cells into explanted mouse heart) and in vivo, where $\sim 500,000$ cells were directly injected into the anterior left ventricular wall of rats. It was reported that $\mathrm{hESCs}$ were not affected by magnetic labeling and maintained their ability to proliferate and differentiate. T2-weighted MRI revealed well-defined hypointense areas at the site of hESC injection, which demonstrated that magnetic labeling of hESCs can serve as a valuable tool for in vivo tracking of these cells. In other reports, MRI has also been used to monitor cell therapy and assess cardiac function recovery in mouse models of myocardial infarction [21-23].

A similar strategy was adopted to image transplanted hESCs in rats with a cortical or spinal cord lesion [24]. It was found that the cells migrated to the lesion during the first week after 
transplantation, as indicated by MRI as a hypointense signal which persisted for more than 30 days. Subsequently, new polycation-bound SPIO nanoparticles were designed to image hESCs with higher intracellular uptake efficiency, as well as less effect on cell viability [25]. SPIO nanoparticle labeling can also be used to evaluate stem cell-based therapies in degenerative central nervous system disorders such as Parkinson's disease. Recently, one such study was carried out in a rat model of Parkinson's disease where magnetically labeled hESCs were tracked by high-field MRI for 6 months [26].

With magnetically labeled hESC-derived neurospheres, serial MRI scans were performed to assess the migration of transplanted cells in a mouse model of multiple sclerosis (Fig. (1A)) [27]. It was found that cell migration occurred along the white matter tracts, predominantly early in the acute phase of disease in an asymmetric manner. For the first time, this study showed that hESC-derived neural precursors respond to tissue signals in a multiple sclerosis model, which may provide invaluable insights not only for designing and optimizing cell therapies for multiple sclerosis but also in better understanding of in vivo cell dynamics and cell-tissue interactions.

Apart from SPIO nanoparticles, manganese (Mn)-based reagents have also been reported for monitoring hESCs with MRI [28]. To overcome one of the key disadvantages of SPIO nanoparticle labeling for MRI applications (i.e. it can not differentiate viable cells from dead cells), MRI tracking of cells with $\mathrm{Mn}^{2+}$ is based on the rationale that manganese chloride $\left(\mathrm{MnCl}_{2}\right)$ enters the cells via voltage-gated calcium channels when the cells are biologically active, and accumulates intracellularly to generate a T1-shortening effect. Therefore, Mnbased MRI can be useful for monitoring cell viability after transplantation of hESCs into the myocardium. Recently, this technique was demonstrated in vivo, where the viability of $\mathrm{Mn}^{2+}$-labeled cells was validated by BLI (Fig. (1B)) [29]. It was suggested that $\mathrm{MnCl}_{2-}$ labeling may also be applicable for assays of cell viability, proliferation, and apoptosis.

The advantages of MRI lie in its high spatial resolution and good tissue penetration, which can enable visualization of the labeled cells with good anatomical accuracy. However, the sensitivity of MRI is not as high as many other imaging modalities (e.g. BLI, SPECT, and PET). Further, dilution of the signal when cells divide, inability to differentiate viable from dead cells, and uptake of SPIO nanoparticles by macrophages after hESCs die, are also major concerns for MRI-based hESC tracking. One interesting study was carried out to compare MRI- and BLI-based hESC tracking, using luciferase-expressing hESCs and hESCderived endothelial cells (hESC-ECs) which were labeled with SPIO nanoparticles before transplantation into the hind limbs of mice [30]. Longitudinal MRI showed persistent signals in both cell populations that lasted up to 4 weeks. However, BLI indicated distinct signal patterns for hESCs and hESC-ECs. It was concluded that BLI can be a better tool for monitoring cell biology (e.g. viability and ability to differentiate) while MRI is superior in high-resolution detection. In the next section, we will discuss the tracking of hESCs and hESC-derived cells in vivo by optical imaging techniques (both bioluminescence and fluorescence).

\section{IMAGING hESCS WITH OPTICAL TECHNIQUES}

Optical imaging is less expensive and more convenient than the other imaging modalities such as MRI and PET. Therefore, it can serve as an attractive alternative in preclinical imaging studies since light penetration in small animals is less of a concern than in humans. In small animal models, optical imaging (including BLI and fluorescence) is able to longitudinally detect transplanted cells sensitively and reliably which has significantly facilitated the understanding of the spatial-temporal kinetics of hESC engraftment, proliferation, and teratoma formation in living subjects [31]. In many studies, both BLI and 
fluorescence imaging are incorporated for different purposes which can be complementary to each other. Generally, fluorescence imaging is more useful in tagging individual cells or evaluation of the transfection efficiency in the cell population. On the other hand, BLI is very sensitive since it has virtually non-existent background signal, a major limitation for fluorescence imaging even in the near-infrared (NIR, 700-900 $\mathrm{nm}$ ) range [32,33]. BLI has been frequently employed in hESC-based studies in small animal models.

\section{Bioluminescence Imaging}

A double-fusion construct with a ubiquitin promoter driving both enhanced green fluorescent protein (eGFP) and the firefly luciferase (fLuc) was used for in vitro and in vivo studies of hESCs [34]. Comparison of the transfection efficiency and viability of various techniques in two hESC lines (male $\mathrm{H} 1$ and female $\mathrm{H} 9$ cells) revealed that lentiviral transduction generated a greater number of hESC lines which stably express the doublefusion reporter gene than the other transfection techniques. Following subcutaneous transplantation into immunodeficient nude mice, the transfected cells exhibited robust proliferation as evidenced by longitudinal BLI.

BLI was used to assess the viability of hESC-derived skeletal myoblasts after transplantation into the tibialis anterior muscle of mice (Fig. (2)) [35]. The hESC-derived myoblasts were transduced with a lentiviral vector carrying a triple-fusion reporter construct which expresses the herpes simplex virus thymidine kinase (HSV-tk), eGFP, and fLuc, all under the control of a cytomegalovirus (CMV) promoter. In another report, hESC-derived neural precursors were transduced with a similar strategy for monitoring their long-term graft viability in immunodeficient mouse models with BLI [36]. Many other studies have focused on monitoring the in vivo behavior of other hESC-derived cells with BLI, such as insulinproducing cells which could be used for treating diabetes [37], hepatocyte-like cells [38], and mesenchymal stromal cells [39].

Since potential development of teratoma is a significant concern for hESC-based therapies, BLI was used to investigate the relationship between the number of hESCs and teratoma formation in a xenogenic model [40]. Different numbers of hESCs (H9) stably transduced with eGFP and fLuc, driven by a human ubiquitin promoter, were injected into immunodeficient mice, either intra-myocardially or into the skeletal muscle. BLI over two months after transplantation revealed that a minimum of $1 \times 10^{5} \mathrm{hESCs}$ in the myocardium and $1 \times 10^{4} \mathrm{hESCs}$ in the skeletal muscle were needed for teratoma development, respectively, suggesting that the number of hESCs may be a critical factor in teratoma formation.

Based on the current literature data, whether hESCs have immune-privileged properties remains controversial. To address this issue, BLI was employed to investigate the fate of transplanted hESCs expressing both fLuc and eGFP [41]. It was found that hESCs were immunogenic, triggering both cellular and hormonal-mediated pathways, and as a result were rapidly rejected in xenogenic hosts. In another study with immunodeficient mice, fLucexpressing hESC-derived CD $34^{+}$cells demonstrated stable engraftment and cell expansion in vivo over several months after transplantation into the liver [42]. In vitro, these $\mathrm{hESC}$ derived $\mathrm{CD} 34^{+}$cells could generate both hematopoietic and endothelial lineages, however with the latter being dominant. Therefore, although transplanted hESC-derived CD34 ${ }^{+}$cells are suitable for revascularization therapies, additional measures will be needed to provide higher levels of long-term hematopoietic engraftment. Over the last several years, BLI has rapidly evolved into an indispensable tool for high-throughput, inexpensive, sensitive, and longitudinal tracking of cell proliferation in small animal models over periods of up to several months, which has provided rich and invaluable insights into various biological questions which could not be readily interrogated previously [43]. 


\section{Fluorescence Imaging}

For fluorescence imaging of hESC and its derivatives, fluorescent proteins are the most frequently used labels. When implanted into immunocompromised mice, hESCs can develop teratomas which contain complex structures comprising differentiated cell types representing the major germ line-derived lineages. In one early study, GFP was used to study the growth and invasiveness of human cancer cells in teratomas formed by hESCs, which allowed tracking of tumor cell invasion and recruitment of human teratoma-derived blood vessels $[44,45]$. In another report, lipofection was used to generate hESC lines expressing fluorescent proteins without affecting their pluripotency, which may find widespread use such as small interfering RNA-based studies of gene expression/function [46].

For myocardial regeneration applications of hESCs, visualization and isolation of large numbers of fluorescently labeled, functional cardiomyocytes from hESCs is needed. Recently, methods for the creation of pure populations of hESCs and cardiomyocytes were described, with ubiquitous or specific promoters which direct the expression of fluorescent proteins, to visualize and track cardiomyocytes and their progenitors [47]. The phosphoglycerate kinase (PGK) promoter was used to ubiquitously drive the expression of histone-2B fused eGFP to the nucleus to monitor the DNA content and enable tracking of cell migration and lineage. This selection protocol yielded $96 \%$ pure cardiomyocytes that could be cultured for over 4 months.

To reveal the full potential of hESCs, it would be desirable to be able to genetically alter them as is routinely done with mouse embryonic stem cells. In one pioneering study, the identification of the human homolog of the mouse Rosa26 locus, which is useful for genetic modification and can be targeted with high efficiency, was reported [48]. Targeting of a red fluorescent protein (RFP) cDNA to this locus was achieved through homologous recombination which could be readily detected in multiple hESC-derived lineages. Since the hRosa26 locus is active throughout differentiation, this strategy should allow diverse genetic manipulations such as gain-of-function, loss-of-function, and lineage-tracing studies.

Besides fluorescent proteins, other fluorescent agents (such as fluorescent nanoparticles and dyes) can also used for fluorescence imaging of hESC and its derivatives [49]. A fluorescent dye, indocyanine green (ICG) which was approved by the FDA for various clinical uses such as ophthalmic angiography, has been tested for hESC labeling [50]. Cellular uptake of ICG was via adherence and diffusion of the dye across the phospholipid cell membrane bilayer and addition of a transfection agent (e.g. protamine sulfate) was found to significantly improve its uptake. Recently, this labeling technique was further developed for both hESCs and hESC-derived cardiomyocytes [51]. Fluorescent signal of labeled hESCs and hESC-derived cardiomyocytes was found to be significantly higher than the pre-contrast data for up to 48 hours. Another fluorescent dye, DiD, has also been used to label and track hESC-derived neural stem cells in a mouse model of brain damage [52]. The location of injected cells within the mouse brain could be determined through DiD fluorescence and immunodetection of human-specific nestin and nuclear antigen at up to a week after transplantation.

\section{IMAGING hESCS WITH RADIONUCLIDE-BASED TECHNIQUES}

Radionuclide-based imaging techniques (i.e. SPECT and PET), with high sensitivity and being readily translatable into clinical practice, can also be used for hESC tracking [53]. For SPECT imaging applications, ${ }^{111}$ In-oxine has been approved by the FDA for tracking various cell types in clinical studies [19]. However, the use of this agent for hESC tracking has not been well studied. In one report, the feasibility of small animal SPECT in assessing 
the accumulation of ${ }^{111}$ In-oxine-labeled hESC-derived neural progenitors and rat hippocampal progenitors after intravenous or intra-arterial administration in experimental models of cerebral ischemia was evaluated (Fig. (3A)) [54]. It was found that after intravenous injection, both cell types accumulated primarily into the internal organs instead of the brain. However, a weak signal was nonetheless detectable in the ischemic hemisphere after intra-arterial injection. The detection sensitivity of SPECT in this study was reported to be approximately $1000{ }^{111}$ In-oxine-labeled cells.

PET is one of the most sensitive imaging modalities. Rather than focusing on non-invasive tracking of hESCs per se, one interesting study investigated the potential of various PET tracers in the detection of teratoma formation [55]. Since the biggest concern of hESC-based therapies is teratoma formation, non-invasive imaging of teratomas could be a valuable tool for monitoring patients undergoing hESC treatment. In this study, H9 hESCs stably expressing fLuc and eGFP were subcutaneously injected into adult nude mice. At eight weeks after transplantation, the hESC grafts evolved into teratomas as confirmed by longitudinal BLI. Two of the most widely used PET tracers in the clinic, 2-deoxy-2-18 $\mathrm{F}$ fluoro-D-glucose $\left({ }^{18} \mathrm{~F}-\mathrm{FDG}\right.$, which images glucose metabolism) and $3^{\prime}$-deoxy- $3^{\prime}-{ }^{18} \mathrm{~F}-$ fluorothymidine $\left({ }^{18} \mathrm{~F}-\mathrm{FLT}\right.$, which detects cell proliferation), both failed to detect $\mathrm{hESC}$ derived teratomas. However, another tracer, ${ }^{64} \mathrm{Cu}$-DOTA-RGD4 which binds to integrin av $\beta 3$ [56,57], enabled non-invasive visualization of the teratomas with PET (Fig. (3B)). Ex vivo histology confirmed that both the cells and tumor vasculature within the teratomas expressed high levels of integrin av $\beta 3$, an important protein which regulates tumor angiogenesis [58,59]. This study clearly suggested that imaging integrin av $\beta 3$ expression may have potential clinical applicability in monitoring the tumorigenicity after hESC transplantation.

\section{MULTIMODALITY IMAGING OF hESCS}

The imaging techniques discussed above each has its advantages and limitations. For example, it is difficult to accurately quantify a fluorescence signal in living subjects with fluorescence imaging alone, particularly in deep tissues; MRI has high resolution and good soft-tissue contrast but low sensitivity; BLI is highly sensitive and quantitative yet it suffers from poor tissue penetration; and radionuclide-based imaging techniques are very sensitive but have relatively poor spatial resolution. Combination of multiple imaging modalities may provide complementary information than a single modality alone.

In one report, both BLI and MRI were used to visualize the fate of grafted hESC-derived human neural stem cells (hNSCs) in stroke-damaged rat brain, where MRI provided high spatial resolution and BLI enabled high sensitivity detection of the cells (Fig. (4)) [60]. Cell survival was tracked non-invasively by MRI and BLI for 2 months after transplantation. Histological studies further confirmed that grafted hNSCs differentiated into neurons, oligodendrocytes, and astrocytes.

SPECT and BLI has been used together to monitor hESC engraftment and proliferation in live mice after transplantation, where lentiviral vectors expressing the fLuc and HSV1-tk genes were used for transfection [61]. Constitutive expression of either transgene did not alter the properties of hESCs in the culture and formation of teratomas in immunocompromised mice was investigated to test whether the genetically modified hESCs maintained pluripotency. With BLI, the fLuc-transduced hESCs could be easily detected in mice bearing teratomas long before the tumors became palpable. A substrate of HSV1-tk, 1$\left(2^{\prime}\right.$-deoxy-2'-fluoro-beta-D-arabinofuranosyl)-5- ${ }^{125}$ I-iodouracil $\left({ }^{125}\right.$ I-FIAU, which can be phosphorylated by the HSV1-tk enzyme and retained within transduced cells), was also able to detect the teratomas with SPECT after systemic administration. 


\section{CONCLUSIONS}

A variety of labels and imaging techniques have been explored for labeling and tracking $\mathrm{hESC}$ and its derivatives. Direct labeling of cells with image tags (e.g. with SPIO nanoparticles, fluorescent dyes, ${ }^{111} \mathrm{In}$-oxine, etc.) is easier than indirect labeling in most cases and the safety profiles of direct cell labeling techniques are generally quite good. However, the disadvantage of direct cell labeling is that the label itself is detected rather than the live cells of interest. The labels may leak out of the cells when the cells are alive or be taken up by other cells when the labeled cells die. Therefore, care must be taken when interpreting the experimental results and rigorous validation is certainly needed to obtain more robust and reliable data. With reporter gene techniques (i.e. indirect cell labeling), only live cells are detected thus they can provide more insights about the cell migration, differentiation, and proliferation in vivo.

Each imaging modality has its advantages and disadvantages in terms of sensitivity, tissue penetration, spatial resolution, and clinical potential (Table 1) [15]. Optical imaging is mostly applicable to preclinical studies where light penetration is less of an issue than in patients. BLI can not be used in human studies while tracking of labeled cells with MRI, SPECT, and PET may all potentially be performed in patients. Combination of various imaging modalities can give complementary information. As a matter of fact, many of the reporter gene-based studies of hESCs incorporated multiple reporter genes. For example, fluorescent genes (e.g. GFP and RFP) can facilitate cell sorting, BLI (with luciferases) can enable in vivo long term monitoring of hESCs in a quantitative manner in small animal models, and PET can allow for more clinically relevant, highly sensitive detection of the injected hESCs and/or the daughter cells. Future development and validation of various hESC labeling/tracking techniques will further strengthen the arsenal for cell-based therapy of various diseases.

Safety of cell labeling is always a big concern in potential clinical studies since introduction of foreign substances (e.g. image labels or genes) may cause unpredictable alterations in cells. Based on the available literature data, labeling of cells with SPIO nanoparticles appears to be safe and is in active clinical development. For indirect cell labeling, one of the most intensively studied reporter genes, HSV1-tk, is also a suicide gene which adds an extra layer of control to ensure safety [62]. The ideal imaging modality for tracking hESCs in patients requires the imaging tags to be non-toxic, biocompatible, and highly specific to reduce perturbation to the target cells. Much future effort will be required before this can become a reality and clinical routine.

Stem cell therapy has tremendous therapeutic potential, however, numerous questions still remain unanswered. Non-invasive imaging techniques have proven to be of great value in preclinical and clinical studies for tracking transplanted stem cells, and will continue to guide the future development of hESC-based therapies. With non-invasive imaging techniques, we can eventually determine which cell type is more preferable for a certain disease (e.g. hESCs or certain hESC-derived cells) as well as choose the right delivery methods of the cells (e.g. intravenous, intracoronary, or local injection). Detection and correction of hESC misbehavior (e.g. teratoma formation) is also an important task for imaging. The requirement for hESC tracking techniques depends on the clinical scenario. In some cases, only short term tracking is needed while in other cases, long term survival and proliferation would also need to be monitored. MRI, radionuclide-based imaging techniques, and reporter gene-based approaches will each have their own niches. Rather than identifying and optimizing one technique that is applicable for all clinical scenarios, it is probably more appropriate to optimize how a certain imaging technique/modality can be best used to serve the purpose in a specific situation. The continued evolvement of non-invasive imaging 
techniques will undoubtedly contribute to significant advances in understanding stem cell biology and mechanisms of action.

\section{Acknowledgments}

The authors acknowledge financial support from the UW School of Medicine and Public Health's Medical Education and Research Committee through the Wisconsin Partnership Program, the University of Wisconsin Carbone Cancer Center, NCRR 1UL1RR025011, and a Susan G. Komen Postdoctoral Fellowship.

\section{REFERENCES}

[1]. Thomson JA, Itskovitz-Eldor J, Shapiro SS, Waknitz MA, Swiergiel JJ, Marshall VS, Jones JM. Embryonic stem cell lines derived from human blastocysts. Science. 1998; 282:1145-1147. [PubMed: 9804556]

[2]. Mountford JC. Human embryonic stem cells: origins, characteristics and potential for regenerative therapy. Transfus. Med. 2008; 18:1-12. [PubMed: 18279188]

[3]. Sartipy P, Bjorquist P, Strehl R, Hyllner J. The application of human embryonic stem cell technologies to drug discovery. Drug Discov. Today. 2007; 12:688-699. [PubMed: 17826681]

[4]. Singec I, Jandial R, Crain A, Nikkhah G, Snyder EY. The leading edge of stem cell therapeutics. Annu. Rev. Med. 2007; 58:313-328. [PubMed: 17100553]

[5]. Trounson A. New perspectives in human stem cell therapeutic research. BMC Med. 2009; 7:29. [PubMed: 19519878]

[6]. Guillaume DJ, Zhang SC. Human embryonic stem cells: a potential source of transplantable neural progenitor cells. Neurosurg. Focus. 2008; 24:E3. [PubMed: 18341406]

[7]. Keirstead HS, Nistor G, Bernal G, Totoiu M, Cloutier F, Sharp K, Steward O. Human embryonic stem cell-derived oligodendrocyte progenitor cell transplants remyelinate and restore locomotion after spinal cord injury. J. Neurosci. 2005; 25:4694-4705. [PubMed: 15888645]

[8]. Koelling S, Miosge N. Stem cell therapy for cartilage regeneration in osteoarthritis. Expert Opin. Biol. Ther. 2009; 9:1399-1405. [PubMed: 19793003]

[9]. Xue T, Cho HC, Akar FG, Tsang SY, Jones SP, Marban E, Tomaselli GF, Li RA. Functional integration of electrically active cardiac derivatives from genetically engineered human embryonic stem cells with quiescent recipient ventricular cardiomyocytes: insights into the development of cell-based pacemakers. Circulation. 2005; 111:11-20. [PubMed: 15611367]

[10]. Swijnenburg RJ, van der Bogt KE, Sheikh AY, Cao F, Wu JC. Clinical hurdles for the transplantation of cardiomyocytes derived from human embryonic stem cells: role of molecular imaging. Curr. Opin. Biotechnol. 2007; 18:38-45. [PubMed: 17196814]

[11]. Laflamme MA, Chen KY, Naumova AV, Muskheli V, Fugate JA, Dupras SK, Reinecke H, Xu C, Hassanipour M, Police S, O'Sullivan C, Collins L, Chen Y, Minami E, Gill EA, Ueno S, Yuan C, Gold J, Murry CE. Cardiomyocytes derived from human embryonic stem cells in pro-survival factors enhance function of infarcted rat hearts. Nat. Biotechnol. 2007; 25:1015-1024. [PubMed: 17721512]

[12]. van Laake LW, Passier R, Doevendans PA, Mummery CL. Human embryonic stem cell-derived cardiomyocytes and cardiac repair in rodents. Circ. Res. 2008; 102:1008-1010. [PubMed: 18436793]

[13]. Narsinh KH, Cao F, Wu JC. Molecular imaging of human embryonic stem cells. Methods Mol. Biol. 2009; 515:13-32. [PubMed: 19405224]

[14]. Mankoff DA. A definition of molecular imaging. J. Nucl. Med. 2007; 48:18N, $21 \mathrm{~N}$.

[15]. Massoud TF, Gambhir SS. Molecular imaging in living subjects: seeing fundamental biological processes in a new light. Genes Dev. 2003; 17:545-580. [PubMed: 12629038]

[16]. Cai W, Chen X. Multimodality imaging of vascular endothelial growth factor and vascular endothelial growth factor receptor expression. Front. Biosci. 2007; 12:4267-4279. [PubMed: 17485373]

[17]. Arbab AS, Liu W, Frank JA. Cellular magnetic resonance imaging: current status and future prospects. Expert Rev. Med. Devices. 2006; 3:427-439. [PubMed: 16866640] 
[18]. Budde MD, Frank JA. Magnetic tagging of therapeutic cells for MRI. J. Nucl. Med. 2009; 50:171-174. [PubMed: 19164242]

[19]. Pearl J, Wu JC. Seeing is believing: tracking cells to determine the effects of cell transplantation. Semin. Thorac. Cardiovasc. Surg. 2008; 20:102-109. [PubMed: 18707641]

[20]. Tallheden T, Nannmark U, Lorentzon M, Rakotonirainy O, Soussi B, Waagstein F, Jeppsson A, Sjogren-Jansson E, Lindahl A, Omerovic E. In vivo MR imaging of magnetically labeled human embryonic stem cells. Life Sci. 2006; 79:999-1006. [PubMed: 16828117]

[21]. van Laake LW, Passier R, Monshouwer-Kloots J, Nederhoff MG, Ward-van Oostwaard D, Field LJ, van Echteld CJ, Doevendans PA, Mummery CL. Monitoring of cell therapy and assessment of cardiac function using magnetic resonance imaging in a mouse model of myocardial infarction. Nat. Protoc. 2007; 2:2551-2567. [PubMed: 17947998]

[22]. Henning TD, Boddington S, Daldrup-Link HE. Labeling hESCs and hMSCs with iron oxide nanoparticles for non-invasive in vivo tracking with MR imaging. J. Vis. Exp. 2008 ID=685.

[23]. Chung J, Yamada M, Yang PC. Magnetic resonance imaging of human embryonic stem cells. Curr. Protoc. Stem Cell Biol. 2009 Chapter 5, Unit 5A 3.

[24]. Sykova E, Jendelova P. Magnetic resonance tracking of transplanted stem cells in rat brain and spinal cord. Neurodegener. Dis. 2006; 3:62-67. [PubMed: 16909039]

[25]. Sykova E, Jendelova P. In vivo tracking of stem cells in brain and spinal cord injury. Prog. Brain Res. 2007; 161:367-383. [PubMed: 17618991]

[26]. Stroh A, Boltze J, Sieland K, Hild K, Gutzeit C, Jung T, Kressel J, Hau S, Reich D, Grune T, Zimmer C. Impact of magnetic labeling on human and mouse stem cells and their long-term magnetic resonance tracking in a rat model of Parkinson disease. Mol. Imaging. 2009; 8:166178. [PubMed: 19723474]

[27]. Ben-Hur T, van Heeswijk RB, Einstein O, Aharonowiz M, Xue R, Frost EE, Mori S, Reubinoff BE, Bulte JW. Serial in vivo MR tracking of magnetically labeled neural spheres transplanted in chronic EAE mice. Magn. Reson. Med. 2007; 57:164-171. [PubMed: 17191231]

[28]. Yamada M, Yang P. In vitro labeling of human embryonic stem cells for magnetic resonance imaging. J. Vis. Exp. $2008 \mathrm{ID}=827$.

[29]. Yamada M, Gurney PT, Chung J, Kundu P, Drukker M, Smith AK, Weissman IL, Nishimura D, Robbins RC, Yang PC. Manganese-guided cellular MRI of human embryonic stem cell and human bone marrow stromal cell viability. Magn. Reson. Med. 2009; 62:1047-1054. [PubMed: 19526508]

[30]. Li Z, Suzuki Y, Huang M, Cao F, Xie X, Connolly AJ, Yang PC, Wu JC. Comparison of reporter gene and iron particle labeling for tracking fate of human embryonic stem cells and differentiated endothelial cells in living subjects. Stem Cells. 2008; 26:864-873. [PubMed: 18218820]

[31]. Wilson K, Yu J, Lee A, Wu JC. In vitro and in vivo bioluminescence reporter gene imaging of human embryonic stem cells. J. Vis. Exp. 2008 ID=740.

[32]. Dothager RS, Flentie K, Moss B, Pan MH, Kesarwala A, Piwnica-Worms D. Advances in bioluminescence imaging of live animal models. Curr. Opin. Biotechnol. 2009; 20:45-53. [PubMed: 19233638]

[33]. Cai W, Hsu AR, Li ZB, Chen X. Are quantum dots ready for in vivo imaging in human subjects? Nanoscale Res. Lett. 2007; 2:265-281. [PubMed: 21394238]

[34]. Cao F, Xie X, Gollan T, Zhao L, Narsinh K, Lee RJ, Wu JC. Comparison of gene-transfer efficiency in human embryonic stem cells. Mol. Imaging Biol. 2010; 12:15-24. [PubMed: 19551446]

[35]. Barberi T, Bradbury M, Dincer Z, Panagiotakos G, Socci ND, Studer L. Derivation of engraftable skeletal myoblasts from human embryonic stem cells. Nat. Med. 2007; 13:642-648. [PubMed: 17417652]

[36]. Bradbury MS, Panagiotakos G, Chan BK, Tomishima M, Zanzonico P, Vider J, Ponomarev V, Studer L, Tabar V. Optical bioluminescence imaging of human ES cell progeny in the rodent CNS. J. Neurochem. 2007; 102:2029-2039. [PubMed: 17555555]

[37]. Chan KM, Raikwar SP, Zavazava N. Strategies for differentiating embryonic stem cells (ESC) into insulin-producing cells and development of non-invasive imaging techniques using bioluminescence. Immunol. Res. 2007; 39:261-270. [PubMed: 17917070] 
[38]. Duan Y, Catana A, Meng Y, Yamamoto N, He S, Gupta S, Gambhir SS, Zern MA. Differentiation and enrichment of hepatocyte-like cells from human embryonic stem cells in vitro and in vivo. Stem Cells. 2007; 25:3058-3068. [PubMed: 17885076]

[39]. Laurila JP, Laatikainen L, Castellone MD, Trivedi P, Heikkila J, Hinkkanen A, Hematti P, Laukkanen MO. Human embryonic stem cell-derived mesenchymal stromal cell transplantation in a rat hind limb injury model. Cytotherapy. 2009:1-12. [PubMed: 19562577]

[40]. Lee AS, Tang C, Cao F, Xie X, van der Bogt K, Hwang A, Connolly AJ, Robbins RC, Wu JC. Effects of cell number on teratoma formation by human embryonic stem cells. Cell Cycle. 2009; 8:2608-2612. [PubMed: 19597339]

[41]. Swijnenburg RJ, Schrepfer S, Govaert JA, Cao F, Ransohoff K, Sheikh AY, Haddad M, Connolly AJ, Davis MM, Robbins RC, Wu JC. Immunosuppressive therapy mitigates immunological rejection of human embryonic stem cell xenografts. Proc. Natl. Acad. Sci. USA. 2008; 105:12991-12996. [PubMed: 18728188]

[42]. Tian X, Hexum MK, Penchev VR, Taylor RJ, Shultz LD, Kaufman DS. Bioluminescent imaging demonstrates that transplanted human embryonic stem cell-derived CD34(+) cells preferentially develop into endothelial cells. Stem Cells. 2009; 27:2675-2685. [PubMed: 19711457]

[43]. Wilson KD, Huang M, Wu JC. Bioluminescence reporter gene imaging of human embryonic stem cell survival, proliferation, and fate. Methods Mol. Biol. 2009; 574:87-103. [PubMed: 19685302]

[44]. Tzukerman M, Rosenberg T, Ravel Y, Reiter I, Coleman R, Skorecki K. An experimental platform for studying growth and invasiveness of tumor cells within teratomas derived from human embryonic stem cells. Proc. Natl. Acad. Sci. USA. 2003; 100:13507-13512. [PubMed: 14573705]

[45]. Tzukerman M, Skorecki KL. A novel experimental platform for investigating cancer growth and anti-cancer therapy in a human tissue microenvironment derived from human embryonic stem cells. Methods Mol. Biol. 2006; 331:329-346. [PubMed: 16881525]

[46]. Vallier L, Rugg-Gunn PJ, Bouhon IA, Andersson FK, Sadler AJ, Pedersen RA. Enhancing and diminishing gene function in human embryonic stem cells. Stem Cells. 2004; 22:2-11. [PubMed: 14688386]

[47]. Kita-Matsuo H, Barcova M, Prigozhina N, Salomonis N, Wei K, Jacot JG, Nelson B, Spiering S, Haverslag R, Kim C, Talantova M, Bajpai R, Calzolari D, Terskikh A, McCulloch AD, Price JH, Conklin BR, Chen HS, Mercola M. Lentiviral vectors and protocols for creation of stable hESC lines for fluorescent tracking and drug resistance selection of cardiomyocytes. PLoS One. 2009; 4:e5046. [PubMed: 19352491]

[48]. Irion S, Luche H, Gadue P, Fehling HJ, Kennedy M, Keller G. Identification and targeting of the ROSA26 locus in human embryonic stem cells. Nat. Biotechnol. 2007; 25:1477-1482. [PubMed: 18037879]

[49]. Ferreira L, Karp JM, Nobre L, Langer R. New opportunities: the use of nanotechnologies to manipulate and track stem cells. Cell Stem Cell. 2008; 3:136-146. [PubMed: 18682237]

[50]. Boddington S, Henning TD, Sutton EJ, Daldrup-Link HE. Labeling stem cells with fluorescent dyes for non-invasive detection with optical imaging. J. Vis. Exp. 2008 ID=686.

[51]. Boddington SE, Henning TD, Jha P, Schlieve CR, Mandrussow L, Denardo D, Bernstein HS, Ritner C, Golovko D, Lu Y, Zhao S, Daldrup-Link HE. Labeling Human Embryonic Stem Cell Derived Cardiomyocytes with Indocyanine Green for Noninvasive Tracking with Optical Imaging: An FDA Compatible Alternative to Firefly Luciferase. Cell Transplant. 2009 Epub ahead of print.

[52]. Mueller D, Shamblott MJ, Fox HE, Gearhart JD, Martin LJ. Transplanted human embryonic germ cell-derived neural stem cells replace neurons and oligodendrocytes in the forebrain of neonatal mice with excitotoxic brain damage. J. Neurosci. Res. 2005; 82:592-608. [PubMed: 16247803]

[53]. Shanthly N, Aruva MR, Zhang K, Mathew B, Thakur ML. Stem cells: a regenerative pharmaceutical. Q. J. Nucl. Med. Mol. Imaging. 2006; 50:205-216. [PubMed: 16868534]

[54]. Lappalainen RS, Narkilahti S, Huhtala T, Liimatainen T, Suuronen T, Narvanen A, Suuronen R, Hovatta O, Jolkkonen J. The SPECT imaging shows the accumulation of neural progenitor cells 
into internal organs after systemic administration in middle cerebral artery occlusion rats. Neurosci. Lett. 2008; 440:246-250. [PubMed: 18572314]

[55]. Cao F, Li Z, Lee A, Liu Z, Chen K, Wang H, Cai W, Chen X, Wu JC. Noninvasive de novo imaging of human embryonic stem cell-derived teratoma formation. Cancer Res. 2009; 69:2709_ 2713. [PubMed: 19318556]

[56]. Cai W, Chen X. Multimodality molecular imaging of tumor angiogenesis. J. Nucl. Med. 2008; 49(Suppl 2):113S-128S. [PubMed: 18523069]

[57]. Cai W, Niu G, Chen X. Imaging of integrins as biomarkers for tumor angiogenesis. Curr. Pharm. Des. 2008; 14:2943-2973. [PubMed: 18991712]

[58]. Cai W, Chen X. Anti-angiogenic cancer therapy based on integrin $\alpha_{v} \beta_{3}$ antagonism. Anti-Cancer Agents Med. Chem. 2006; 6:407-428.

[59]. Cai W, Rao J, Gambhir SS, Chen X. How molecular imaging is speeding up anti-angiogenic drug development. Mol. Cancer Ther. 2006; 5:2624-2633. [PubMed: 17121909]

[60]. Daadi MM, Li Z, Arac A, Grueter BA, Sofilos M, Malenka RC, Wu JC, Steinberg GK. Molecular and magnetic resonance imaging of human embryonic stem cell-derived neural stem cell grafts in ischemic rat brain. Mol. Ther. 2009; 17:1282-1291. [PubMed: 19436269]

[61]. Pomper MG, Hammond H, Yu X, Ye Z, Foss CA, Lin DD, Fox JJ, Cheng L. Serial imaging of human embryonic stem-cell engraftment and teratoma formation in live mouse models. Cell Res. 2009; 19:370-379. [PubMed: 19114988]

[62]. Cao F, Drukker M, Lin S, Sheikh AY, Xie X, Li Z, Connolly AJ, Weissman IL, Wu JC. Molecular imaging of embryonic stem cell misbehavior and suicide gene ablation. Cloning Stem Cells. 2007; 9:107-117. [PubMed: 17386018] 

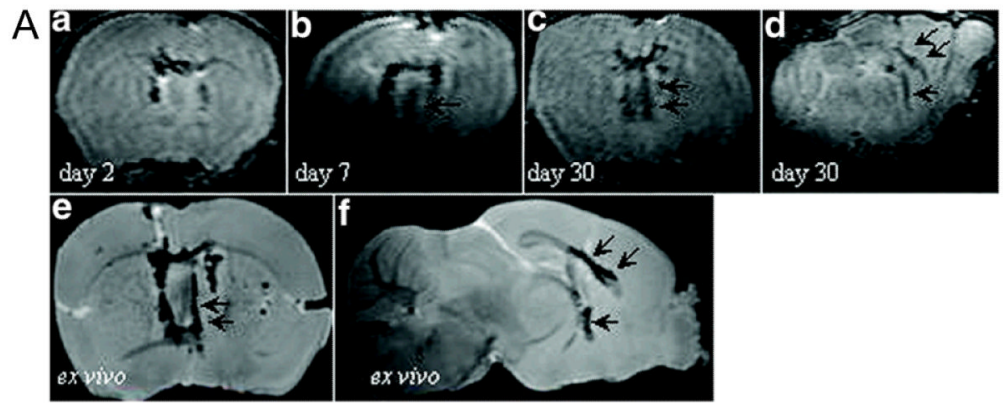

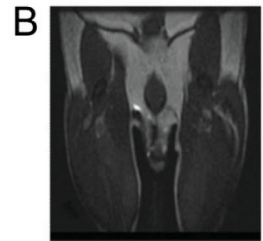

Pre-injection

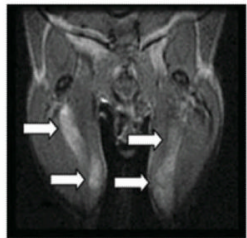

15 min post-injection

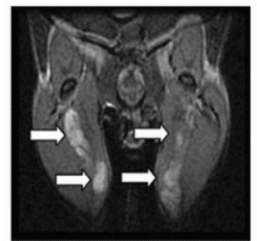

45 min post-injection

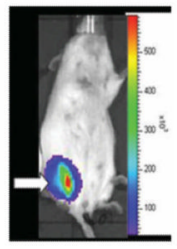

$\mathrm{BLI}$

Fig. (1).

Non-invasive MRI of hESC and its derivatives. A. In vivo MRI of mice transplanted with SPIO nanoparticle-labeled hESC-derived neural precursor cells at day 2 (a), day 7 (b), and day 30 (c: coronal view; d: lateral view) after transplantation. e and f: ex vivo coronal and lateral views corresponding to $\mathrm{c}$ and $\mathrm{d}$, respectively. B. In vivo $\mathrm{Mn}^{2+}$-based MRI of hESCs (arrows) transplanted into the murine hindlimb before and after $\mathrm{MnCl}_{2}$ injection. Corresponding BLI signal of the luciferase-expressing hESCs is also shown. Adapted from [27,29]. 


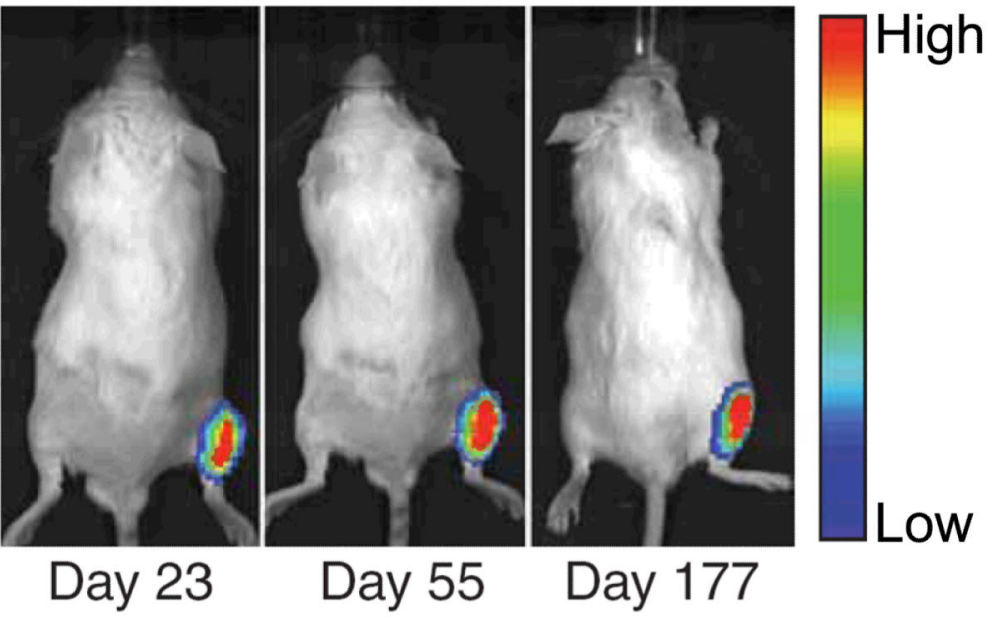

Fig. (2).

In vivo BLI signal overlying the right tibialis anterior graft site in a mouse at days 23,55 and 177 after transplantation of luciferase-expressing hESC-derived myoblasts. Adapted from [35]. 


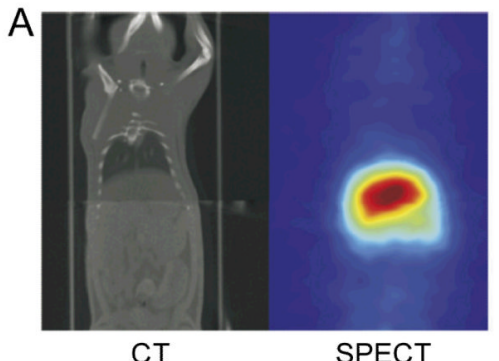

CT

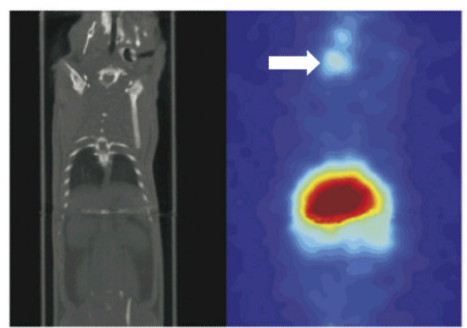

CT
SPECT

B

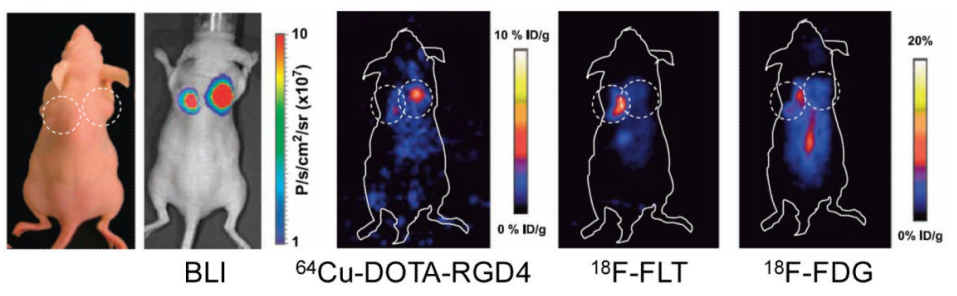

Fig. (3).

Radionuclide-based imaging of hESC and its derivatives. A. Left: Accumulation of ${ }^{111}$ Inoxine-labeled hESC-derived neural cells at $24 \mathrm{~h}$ after femoral vein infusion in stroke rats. Right: After intra-arterial infusion, hESC-derived neural cells were detected in the internal organs as well as in the affected brain area in stroke rats (arrow). B. BLI and PET imaging of hESC-derived teratoma. The photograph and BLI shows teratoma formation by $\mathrm{H} 9$ hESCs at the right shoulder and tumor formation by a control cell line at the left shoulder. Specific and prominent uptake of ${ }^{64} \mathrm{Cu}$-DOTA-RGD4 was observed in the teratoma (high integrin av $\beta 3$ expression) but not in the control tumor (low integrin av $\beta 3$ expression). In contrast, hESC-derived teratomas had low uptake of ${ }^{18} \mathrm{~F}-\mathrm{FDG}$ and ${ }^{18} \mathrm{~F}-\mathrm{FLT}$, whereas the control tumor had high ${ }^{18}$ F-FDG and ${ }^{18}$ F-FLT uptake. Adapted from $[54,55]$. 

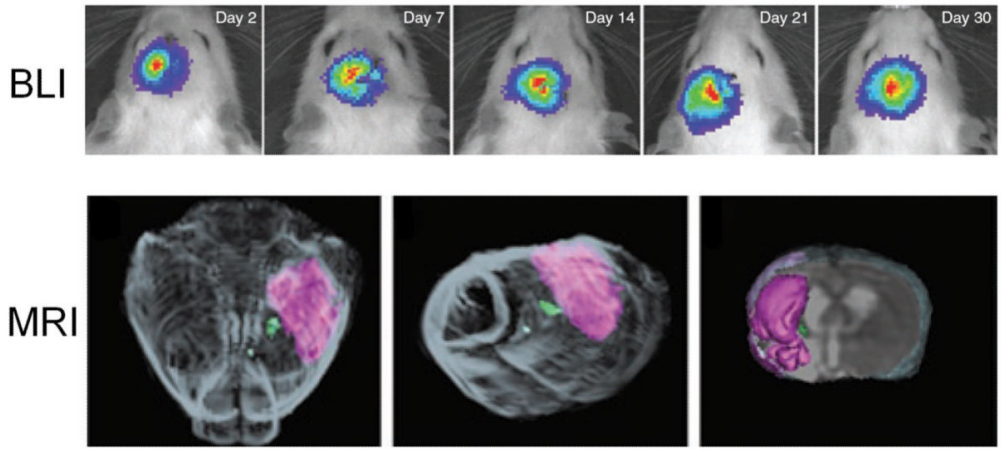

Fig. (4).

Non-invasive tracking of hESC-derived hNSCs. A. Serial BLI of stroke rats transplanted with fLuc-expressing hNSCs. A stable BLI signal suggests the survival and nonproliferative property of the hNSCs. B. MRI of the hNSC grafts in the experimental stroke model. Three-dimensional surface rendering reconstruction of grafted rat brain from high resolution T2-MRI illustrated the graft (green) and stroke (magenta) in a representative animal after injection of 50,000 cells. Adapted from [60]. 
